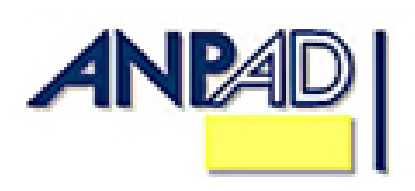

Disponível em

http://www.anpad.org.br/rac

RAC, Curitiba, v. 14, n. 5, art. 4,

pp. 836-853, Set./Out. 2010

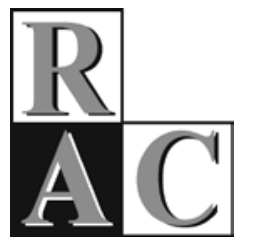

\title{
Programas Sociais Corporativos e Capital Social: Proposta de Qualificação
}

\author{
Corporate Social Programs and Social Capital: a Proposal for Qualification
}

Janaina Macke *

Doutora em Administração de Empresas pela UFRGS. Professora do PPGA/UCS, Caxias do Sul/RS, Brasil.

Rosinha Machado Carrion

Doutora em Administração de Empresas pela UFRGS. Professora do PPGA/UFRGS, Porto Alegre/RS, Brasil.

Eliete Kunrath Dilly Mestranda do PPGA/UCS, Caxias do Sul/RS, Brasil.

* Endereço: Janaina Macke

R. Thomas Edison, 355 / 12, Centro, Farroupilha/RS, 95180-000. E-mail: jmacke@terra.com.br

Copyright (C) 2010 RAC. Todos os direitos, inclusive de tradução, são reservados. É permitido citar parte de artigos sem autorização prévia desde que seja identificada a fonte. 


\section{RESUMO}

Existe um discurso difundido no imaginário social que aponta as empresas como os atores mais qualificados para resolver os problemas sociais, dada a competência que elas vêm demonstrando para enfrentar a concorrência em mercado globalizado e competitivo. No entanto, defende-se que, subjacente a essa visão, está uma visão reducionista da complexidade dos fatos sociais, ao considerar os problemas do campo social como passíveis de serem equacionados pela simples gestão eficiente e eficaz de recursos. O presente artigo foi embasado em pesquisa empírica realizada em sete empresas da região da Serra Gaúcha, agraciadas com o prêmio Responsabilidade Social oferecido pela Assembléia Legislativa do Rio Grande do Sul. O método de trabalho utilizado foi o de estudos de casos múltiplos; como técnica de análise de dados, foi utilizada a análise de conteúdo. Dentre os resultados destacam-se: a fraca intensidade da relação entre empresa e beneficiados, o baixo grau de estruturação dos programas e uma sobreposição de programas atuando com o mesmo público. O artigo aponta os limites de programas sociais de empresas privadas, e propõe, a partir da teoria do capital social, uma proposta para qualificá-los, de modo a potenciar sua contribuição para a construção de uma sociedade mais equilibrada.

Palavras-chave: responsabilidade social empresarial; teoria do capital social; gestão social; avaliação de ações sociais.

\section{ABSTRACT}

There is a discourse that has already spread in the social imaginary that identifies the company as the best qualified actor for solving social problems, given their competence when it comes to facing the globalized and competitive market. Nevertheless, we argue that behind this point of view there is a reductionist view concerning the complexity of social facts, considering social problems simply as efficient and effective management resources. This study is based on empirical research that was conducted in seven enterprises in Rio Grande do Sul State. The companies won the Social Responsibility Award from the Legislative Assembly of Rio Grande do Sul. We used a multiple case study and a content analysis technique. The results show a weak relationship link between companies and the people who benefited, a low level of structured programs and an overlap of programs working with the same target public. The article points out the limits of the social programs and proposes a model - based on the social capital theory - in order to qualify them so that they can strengthen their contribution to building a more balanced society.

Key words: corporate social programs; social capital theory; social management; social actions valuation. 


\section{INTRODUÇÃO}

As ações sociais das empresas compreendem o conjunto das atividades que vão desde doações pequenas e eventuais, até programas/projetos estruturados e com foco preciso, na saúde, na alimentação, na educação e no meio ambiente, ou, enfim, em fatores que contribuam para melhorar as condições de vida de um grupo ou de uma comunidade (Instituto de Pesquisa Econômica Aplicada [IPEA], 2002). Já o conceito de responsabilidade social corporativa é mais abrangente: implica que a empresa responsável conduza "os negócios com o objetivo de se tornar parceira e co-responsável pelo desenvolvimento social” (Guia da Sustentabilidade e Cidadania Corporativa, 2005, p. 59). Atualmente, vem-se observando o crescimento do interesse de empresas privadas em atuar no campo da gestão social (Ashley, 2002; Baiardi \& Laniado, 2002; Carrion, 2000; Melo \& Froes, 1999, 2002; Schommer, 2000). Existem razões bem distintas que levam as organizações a desenvolverem ações sociais. Como motivadores da ação empresarial na área social, Schommer (2002) cita: (i) obtenção de vantagens competitivas, pois os consumidores passam a valorizar ética e participação das empresas na comunidade; (ii) fundamentação religiosa ou moral; (iii) promoção de valores de solidariedade interna e identificação e desenvolvimento de lideranças entre os funcionários; (iv) resposta a incentivos oferecidos pelo governo e (v) orientação e visão estratégica de sobrevivência em longo prazo.

Com o impulso da mídia, não é de surpreender que as pessoas passem a pensar a solução da crise social como problema de gestão dos recursos aplicados no setor, o que legitimaria o papel da empresa para orientar as ações sociais, na medida em que elas detêm o saber gerencial (Carrion, 2003). Portanto, um dos aspectos a ser tratado na questão da responsabilidade social das empresas é a idéia de que elas podem resolver grande parte dos problemas sociais, uma vez que são dotadas de competências gerenciais para tanto. Com isso, as práticas empresariais estão sendo usadas como instrumento de construção de uma ideologia que faz com que a empresa passe a ser vista como o único ator capaz de solucionar a crise social, reduzindo, assim, o problema social a uma questão de gestão de recursos (Carrion, 2003).

A gestão social, para o presente estudo, é mais do que uma gestão voltada para o social, definição que contempla somente a finalidade. Como no estudo de França (2003, p. 2), a gestão social precisa ser compreendida numa perspectiva de aprofundamento da idéia de gestão social que, além da definição do termo pelo seu fim ou sua finalidade, "não menos importante significa pensá-lo enquanto meio, isto é, enquanto processo". A definição de gestão social para este estudo segue, portanto, o pensamento de França (2003, p. 4), que corresponde ao explicitado abaixo.

Modo próprio de gestão, as organizações atuam num circuito que não é, originariamente, aquele do mercado e do Estado, muito embora entretenham, em grande parte dos casos, relações com instituições privadas e públicas, através de variadas formas de parceria para a consecução de projetos. Este é o espaço próprio da chamada sociedade civil, portanto uma esfera pública de ação que não é estatal. As organizações que atuam neste âmbito são sobretudo associações, não perseguem objetivos econômicos. O econômico aparece apenas como meio para a realização dos fins sociais, que podem definir-se também em termos culturais de promoção, resgate ou afirmação identitária etc.; ou fins políticos, no plano de luta por direitos etc.; ou ecológicos, em termos de preservação e educação ambiental etc.; tudo depende do campo de atuação da organização. Esta inversão de prioridades, contrariamente à lógica da empresa privada; condiciona exatamente a especificidade da gestão social. Na prática, entretanto, o exercício de uma gestão social não ocorre sem dificuldades e muitos são os desafios que se impõem.

Contudo, o problema do campo da gestão social é muito mais complexo. E esta é uma questão chave para o presente estudo. Em não se limitando à dimensão gerencial, qual a efetiva contribuição que as empresas teriam a aportar para o enfrentamento da questão social?

Sem entrar na discussão acerca de qual racionalidade orienta tais ações - se instrumental, à medida que visa ao alcance de interesses essencialmente econômicos, ou se substantiva, através da busca de 
um equilíbrio ético-valorativo das ações, conforme discutem Andrade e Medonça (2002) e Serva (1999); ou ainda de que tipo de responsabilidade as empresas estariam imbuídas, o presente estudo se propõe a investigar os investimentos sociais de empresas privadas, sob a ótica da geração de capital social.

O conceito de capital social, ao medir o potencial de produção de riqueza que flui das diversas formas de associação coletiva, permite explorar os impactos da sociedade civil no desempenho econômico (Macke, Vallejos, \& Sarate, 2010). É possível identificar quatro modos principais pelos quais o capital social, encontrado nas redes sociais, estimula o crescimento econômico (Skidmore, 2001, p. 134): (i) níveis elevados de confiança social e fortes normas de reciprocidade reduzem os custos de transação; (ii) as redes sociais diluem os riscos, permitindo que os membros se engajem em inovações e em níveis de riscos mais elevados; (iii) as redes sociais facilitam a rápida disseminação de informações e com isto reduzem as assimetrias; (iv) as redes sociais permitem que seus membros resolvam mais facilmente os problemas de ação coletiva.

Retomando a questão anterior sobre o que seria, de fato, uma contribuição efetiva no campo da gestão social, podemos argumentar que as empresas - e qualquer outro agente - estarão realmente contribuindo para o tratamento dos problemas sociais e para o desenvolvimento local, na medida em que suas ações estejam direcionadas para a geração de capital social.

O desenvolvimento local é marcado pelo contexto em que se situa e pode ser considerado como o "conjunto de atividades culturais, econômicas, políticas e sociais - vistas sob a ótica intersetorial e transescalar - que participam de um projeto de transformação consciente da realidade local” (Milani, 2004, p. 1). Trata-se de um processo orgânico, portanto, não padronizado, uma vez que envolve comportamentos e valores locais. O local compreende um entorno ecossocioterriotorial, onde os recursos de capital social disponíveis podem levar à construção das múltiplas dimensões do desenvolvimento social, político, ambiental, cultural, tecnológico e institucional (Silveira, Bocayuva, \& Zapata, 2001).

Assim sendo, a tese que defendemos - tendo-se presente que diversas empresas se afirmam como responsáveis socialmente, e capazes de solucionar os problemas do campo social, é esta: para que os investimentos sociais das empresas privadas, consideradas responsáveis socialmente, contribuam para o desenvolvimento local, faz-se necessário que suas ações incorporem os princípios da comunidade cívica e, assim, contribuam para o alargamento do capital social da comunidade com a qual interagem.

Dessa forma, o presente estudo tem como objetivo avaliar as implicações das ações sociais de empresas privadas, consideradas responsáveis socialmente, na expansão do capital social das comunidades envolvidas.

\section{CAPITAL SOCIAL: CONCEITOS E DIMENSÕES}

As comunidades que possuem alto nível de capital social são chamadas de comunidades cívicas. Numa comunidade cívica os cidadãos buscam, nas palavras de Tocqueville (2004), o interesse próprio corretamente entendido, ou seja, um interesse definido a partir do contexto das necessidades públicas. As principais características da comunidade cívica são: (i) a cidadania implica direitos e deveres iguais para todos; (ii) a comunidade é unida por relações horizontais de reciprocidade e cooperação, enquanto relações verticais de autoridade e dependência estão pouco presentes; (iii) seus líderes consideram-se responsáveis por seus concidadãos; (iv) há uma ampla participação dos cidadãos no governo; (v) prevalece o espírito público entre os cidadãos; (vi) predominam as relações de confiança entre os membros (Putnam, 2002). 
As normas de reciprocidade e os sistemas de participação cívica são a chave da prosperidade, gerando círculos virtuosos de estímulo ao civismo. Estes círculos virtuosos, a que Putnam (2002) se refere, são caracterizados pela produção de capital social.

O capital social pode aparecer sob muitas formas - confiança, normas e cadeias de relações sociais - e todas estas formas são recursos cuja oferta aumenta com o uso e que se esgotam sem sua utilização (Hirschman, 1984). Além disso, o capital social traz consequências para a ação (Nahapiet \& Ghoshal, 1998; Putnam, 2002). Uma consequência é que o capital social aumenta a eficiência da ação; Putnam (2002) até sustenta que altos níveis de confiança reduzem o oportunismo e a necessidade de custos de monitoramento ao longo do processo. Outra consequência está relacionada ao encorajamento do comportamento cooperativo, por meio do incentivo em desenvolver novas formas de organização.

Desde o surgimento do conceito, ele vem sendo utilizado para explicar uma série de fenômenos sociais (Vallejos, Macke, Olea, \& Toss, 2008). Grande parte das pesquisas tem focado o papel do capital social no desenvolvimento do capital humano (Coleman, 1990), das regiões (Macke et al., 2010; Putnam, 2002), de países (Fukuyama, 1996, 2000) e no desempenho econômico (Baker, 1990 como citado em Nahapiet \& Ghoshal, 1998).

A proposição central da teoria do capital social é que as redes de relacionamentos constituem importante recurso na condução dos assuntos sociais, proporcionando a seus membros um capital coletivo, espécie de credencial que provê crédito nos vários sentidos da palavra (Bourdieu, 1986 como citado em Nahapiet \& Ghoshal, 1998, p. 243).

Grande parte deste capital está relacionada às redes de conhecimento e reconhecimento mútuo, as quais envolvem sentimentos de gratidão, respeito e amizade. Contudo, também é possível encontrar capital social sob a forma de status e reputação social (Bourdieu, 2003a, 2003b), usualmente, quando o pertencimento à determinada rede for algo restrito. Para Bourdieu (2003a) o capital está relacionado à posição de um ator no espaço social, já que influencia a ação que, por sua vez, influencia a posição do ator no campo. Baker (1990 como citado em Nahapiet \& Ghoshal, 1998) limita a definição de capital social à estrutura das redes de relacionamento, enquanto outros autores, entre eles Bourdieu (2003a, 2003b) e Putnam (2002), incluem em suas definições os recursos reais e potenciais que podem ser acessados por meio destas redes.

Para o presente estudo, é adotado o conceito de capital social de Putnam (2002), influenciado por Coleman (1990), já que ele foi testado e utilizado em outras pesquisas, como nos estudos de Nahapiet e Ghoshal (1998) e de Onyx e Bullen (2000). As diferentes definições de capital social são apresentadas na Tabela 1, a seguir. Para Putnam (2002) o capital social é um atributo do tecido social, que normalmente constitui bem público, ao contrário do capital convencional, que costumeiramente é bem privado. Ver Tabela 1.

Tabela 1

Definições de Capital Social Encontradas na Literatura

\begin{tabular}{|c|c|}
\hline Referência & Definição \\
\hline Coleman (1990, p. 302) & $\begin{array}{l}\text { "aquelas características da organização social, tais como confiança, normas e redes que } \\
\text { podem melhorar a eficiência da sociedade, por facilitarem ações coordenadas". }\end{array}$ \\
\hline Putnam (2002, p. 117) & $\begin{array}{l}\text { "Aqui [na comunidade cívica] o capital social diz respeito a características da organização } \\
\text { social como confiança, normas e sistemas, que contribuem para aumentar a eficiência da } \\
\text { sociedade, facilitando ações coordenadas”. }\end{array}$ \\
\hline $\begin{array}{l}\text { Nahapiet e Ghoshal (1998, p. } \\
\text { 243) }\end{array}$ & $\begin{array}{l}\text { "capital social é a soma dos recursos reais e potenciais envolvidos, avaliados e derivados } \\
\text { das redes de relacionamento tidas por um indivíduo ou unidade social”. }\end{array}$ \\
\hline $\begin{array}{l}\text { Franco (2002 como citado em } \\
\text { Melo \& Froes, 2002, p. 54) }\end{array}$ & $\begin{array}{l}\text { "capital social são os níveis de participação e de organização que uma sociedade possui. Se } \\
\text { a sociedade não está tramada, na sua base, por miríades de organizações, se ela não tem } \\
\text { iniciativa, se a confiança social entre os grupos sociais não existe ou é pequena, você } \\
\text { também não pode ter desenvolvimento, nem mesmo crescimento econômico sustentável”. }\end{array}$ \\
\hline
\end{tabular}

Continua 


\section{Tabela 1 (continuação)}

\begin{tabular}{cl}
\hline Referência & \multicolumn{1}{c}{ Definição } \\
\hline Bourdieu (2003a, p. 134) & “O capital representa um poder sobre um campo (num dado momento) e mais \\
& precisamente, sobre o produto acumulado do trabalho passado ... As espécies de capital, \\
& à maneira dos trunfos num jogo, são os poderes que definem as probabilidades de ganho \\
num campo determinado. ... A posição de um determinado agente...”.
\end{tabular}

Baker (1990 como citado em Portes, 1998, p. 6)

Jacobs (1965 como citado em Nahapiet \& Ghoshal, 1998, p. 243)

Loury (1977 como citado em Portes, 1998, p. 4)

Constantini (2002, p. 224)

(Fontes, 1999 como citado em Scherer-Warren, 2002, p. 66).

World Bank (2004)

Baiardi e Laniado (2002, p. 316)

Silveira (2002, p. 243)

"um recurso que os atores derivam de estruturas sociais específicas e então os usam para perseguir seus interesses; é criado através das trocas nas relações entre os atores”.

O termo capital social, inicialmente surgido nos estudos sobre comunidades, destaca a importância chave - para a sobrevivência e funcionamento das comunidades - das fortes redes de relacionamento pessoal desenvolvidas ao longo do tempo, as quais proveem a base para a confiança, cooperação e ação coletivas nestas comunidades.

O conceito de capital social para Loury captura a diferença de acesso às oportunidades através de laços sociais para minorias e não-minorias, mas ele não trabalha com uma definição sistemática das relações do capital social com outras formas de capital.

“conjunto de elementos - tais como, as relações entre atores, o nível de confiança, a capacidade de agregação de grupos e empresas, etc. - que facilitam a produção de atividades sociais e econômicas, em presença de recursos e iniciativa social”.

"O estoque de capital social disponível numa comunidade vai determinar o que Fontes denomina 'sustentabilidade das organizações voluntárias', uma vez que se encontram estruturadas nas comunidades sob a forma de redes sociais para os 'empreendimentos de práticas, visando à produção de bens públicos ... [construírem] suas identidades a partir da idéia de comunidade, locais de convivibilidade e de estabelecimento de laços de pertencimento, que se traduzem no esforço coletivo para a produção do bem comum”.

"as instituições, relações e normas que conformam a qualidade e a quantidade das interações sociais de uma sociedade”.

“o capital social distingue-se de outras formas de capital porque sua disponibilidade não depende de uma dotação da natureza, nem de um processo de acumulação original, nem de investimentos prévios e nem mesmo de capacitação de recursos humanos. No contexto de hoje, depende, única e exclusivamente, da capacidade que tiveram os membros de uma comunidade de praticar o civismo, de engajar-se em empreitadas de bem comum, confiando que estas iniciativas não sejam isoladas porque abrangem sempre um espectro maior da comunidade".

“capital social refere-se à experiência associativa, aos laços de confiança e cooperação, às competências e capacidades organizacionais e às configurações de caráter tácito ou institucionalizado que sedimentam relações interpessoais e interorganizacionais, passíveis de abordagem na ótica de construção social dos territórios”.

Nota. Fonte: Macke, J. (2006). Programas de responsabilidade social corporativa e capital social: contribuição para o desenvolvimento local? ( p. 76).Tese de doutorado, Universidade Federal do Rio Grande do Sul, Porto Alegre, RS, Brasil.

O capital social reside nas relações, ou seja, não é propriedade exclusiva de indivíduos. O desenvolvimento do capital social é, então, significativamente afetado por fatores que moldam a evolução das relações sociais. Para Nahapiet e Ghoshal (1998) existem quatro fatores fundamentais: tempo, interdependência, interação e isolamento.

No estudo sobre o capital social e sua importância na criação de capital intelectual, Nahapiet e Ghoshal (1998) propõem três dimensões de capital social: a estrutural, a relacional e a cognitiva (ver Tabela 2). Embora os autores tenham analiticamente compreendido o capital social em dimensões, apontam que grande parte das características estudadas é altamente relacionada, o que não invalida a classificação, pois facilita a compreensão do construto.

Na face estrutural do capital social analisam-se: presença ou não de laços entre os atores, configuração ou morfologia da rede - descrevendo os padrões de ligações, através de variáveis como densidade, conectividade e hierarquia - e intencionalidade da rede - ou seja, se esta foi criada para um objetivo e está sendo usada para outro (Coleman, 1990). Ainda segundo Nahapiet e Ghoshal (1998), a dimensão estrutural do capital social influencia o desenvolvimento das outras dimensões - a relacional e a cognitiva. Outro aspecto a ser destacado é que nem todas as dimensões do capital social se 
reforçam mutuamente; por exemplo, uma rede eficiente, em termos estruturais, pode não ser a melhor maneira de desenvolver um forte capital relacional ou cognitivo. Ver Tabela 2.

Tabela 2

\section{Dimensões do Capital Social}

\begin{tabular}{lll}
\hline Dimensão Estrutural & Dimensão Cognitiva & Dimensão Relacional \\
\cline { 2 - 3 } Conexões da rede & Códigos e linguagem & Confiança \\
Configuração da rede & compartilhados & Normas \\
Adequação da organização & Narrativas compartilhadas & Obrigações e expectativas \\
& & Identificação social
\end{tabular}

Nota. Fonte: adaptado de Nahapiet, J., \& Ghoshal, S. (1998). Social capital, intellectual capital and the organizational advantage (p. 251). Academy of Management Review, 23(2), 242-266.

O ponto de vista relacional descreve o tipo de relacionamento pessoal, desenvolvido através de uma história de interações (Granovetter, 1992). Este conceito foca aspectos que influenciam os comportamentos, como respeito e amizade, os quais irão determinar a sociabilidade, aceitação e prestígio.

A terceira dimensão do capital social, a qual Nahapiet e Ghoshal (1998) chamaram de cognitiva, se refere aos recursos de que promanam visões compartilhadas, interpretações e sistemas de significado, principalmente códigos e narrativas compartilhados. Estas dimensões do capital social serviram de base para a construção dos instrumentos de coleta de dados discutidos na seção a seguir.

\section{METODOLOGIA}

O método de trabalho adotado foi o de estudo de casos, de natureza explanatória, ou seja, preocupa-se em investigar relações entre elementos que explicam determinado fenômeno (Yin, 1994). Sendo assim, foram investigados os casos mais expressivos de ações sociais de empresas instaladas na região da serra gaúcha. O critério de seleção das empresas foi seu reconhecimento perante a sociedade, através de premiações ou certificados de responsabilidade social. Para cada empresa foi escolhido um programa de atuação junto à comunidade, contemplando, no total, a análise de sete programas sociais de empresas diferentes.

As fontes de evidência utilizadas foram: análise documental, entrevistas semi-estruturadas e observação direta. Foram construídos dois instrumentos de coleta de dados para orientar as entrevistas realizadas: um direcionado aos representantes da empresa e outro às pessoas da comunidade atingida pelas ações sociais. Os instrumentos foram elaborados a partir da revisão teórica e, em especial a partir dos instrumentos de coleta de dados do projeto da Rede Pintadas na Bahia (Milani, 2004). Resumidamente, podemos apresentar aqui, para cada dimensão do capital social, os elementos mais significativos, a partir dos quais as questões foram derivadas (Tabela 3). 
Tabela 3

\section{Proposta de Indicadores Qualitativos de Capital Social para Programas de Empresas Privadas}

\begin{tabular}{|c|c|}
\hline Dimensão do Capital Social & Elementos \\
\hline \multirow[t]{7}{*}{ Relacional } & Participação dos atores \\
\hline & Tomada de decisões \\
\hline & Estímulo à participação e mobilização da comunidade \\
\hline & Identificação e qualificação dos problemas sociais \\
\hline & Intenção de reeditar o programa \\
\hline & Acompanhamento dos beneficiários \\
\hline & Resultado esperado para a comunidade \\
\hline \multirow[t]{5}{*}{ Estrutural } & Organizações parceiras \\
\hline & Iniciativas locais \\
\hline & Contribuições da comunidade para o programa \\
\hline & Mudanças realizadas em função de sugestões da comunidade \\
\hline & Interesse em formar outras parcerias \\
\hline \multirow[t]{7}{*}{ Cognitiva } & Capacitações necessárias para atuar no campo social \\
\hline & Dificuldades encontradas \\
\hline & Valores da empresa e a forma como os coloca em prática \\
\hline & Significado do programa para a empresa \\
\hline & Divulgação das ações \\
\hline & Metodologia de avaliação dos resultados do programa \\
\hline & Indicadores de avaliação dos resultados do programa \\
\hline
\end{tabular}

Nota. Fonte: com base em Milani, C. (2004). Teorias do capital social e desenvolvimento local: lições a partir da experiência de Pintadas (Bahia, Brasil) (pp. 1-10). Recuperado em 08 junho, 2004, de http://www.adm.ufba.br/capitalsocial

Para análise dos dados recorreu-se à técnica de análise de conteúdo, proposta por Bardin (1977), que é uma ferramenta de investigação, cuja finalidade é a interpretação dos conteúdos comunicados, mediante uma descrição objetiva, sistemática e quantitativa destes conteúdos. A análise de conteúdo permite a explicitação e sistematização do conteúdo das mensagens e da expressão deste conteúdo. As categorias de análise foram previamente definidas a partir do estudo de Nahapiet e Goshal (1998) e foram, portanto, centrais, na confecção dos instrumentos.

\section{Os Programas SociaIS EM ANÁlise E O CONTEXTO LoCAL}

Em duas pesquisas realizadas sobre a avaliação dos níveis de capital social no Estado do Rio Grande do Sul - Monastério (2003) e Bandeira (2003) - a região da serra gaúcha foi apontada como possuindo um dos mais altos níveis de capita social do Estado. Assim, foram escolhidas sete empresas desta região: para cada uma, se avaliou o programa/ projeto social mais expressivo e sua repercussão junto às comunidades beneficiadas.

No caso da empresa A, foi escolhido o programa de formação profissional (de operador eletromecânico) destinado a jovens com idade entre 16 e 17 anos, em condições de vulnerabilidade social. Todos os jovens têm aproveitamento garantido nas diversas áreas da empresa, recebendo, no 
período do programa, uma bolsa de estudos, além de todos os benefícios oferecidos aos demais colaboradores da empresa.

A empresa B trabalha com projeto voltado para crianças e adolescentes de um bairro pobre de Caxias do Sul. As atividades são realizadas pelos próprios funcionários e transcorrem duas vezes por semana: é servido almoço, são realizadas palestras educativas e acompanhamento dos temas de casa.

A empresa C patrocina e apóia diversos projetos e entidades beneficentes - sendo grande parte das ações pontuais e localizadas. As ações ocorrem em diferentes áreas, como preservação do meio ambiente, combate à violência e às drogas e doações de cestas básicas, agasalhos, medicamentos e material de construção.

A empresa D proporciona oficinas culturais de caráter profissionalizante (teatro, dança, palestras educativas e atividade esportivas) para crianças de 4 a 18 anos, em situação de vulnerabilidade social, no turno inverso à escola. De forma semelhante, a empresa $\mathbf{E}$ também trabalha com oficinas profissionalizantes, mas com crianças de 7 a 14 anos.

A Empresa $\mathbf{F}$ possui um conjunto de ações em que os funcionários atuam na comunidade, destacando-se a conscientização ambiental, através da entrega de folders e sacos de lixo aos moradores de bairros carentes e a ação de um grupo de funcionários que, vestidos de personagens infantis, vão até o hospital da cidade para brincar e divertir as crianças.

Finalmente, o projeto da empresa $\mathbf{G}$ faz parte de uma rede que funciona por meio do sistema de franquia social. As empresas franqueadas abrem espaço para a formação pessoal e profissional de adolescentes de baixa renda em suas próprias dependências, encaminhando-os posteriormente ao mercado de trabalho.

A maioria das empresas do estudo tem o seguinte perfil: indústria metal-mecânica de grande porte, que desenvolve ações sociais com foco no município há mais de 7 anos; estas ações são essencialmente voltadas à educação de crianças e adolescentes, implicando uma média de investimento financeiro superior a 180 mil reais; ademais, há atuação no campo social motivada principalmente por interesse da presidência.

\section{Programas Sociais Privados e Capital Social}

Como forma de responder ao objetivo proposto, faremos, inicialmente, algumas observações relevantes sobre como os estudos de caso, de forma geral, diferenciam-se uns dos outros. Podemos apontar, basicamente, quatro aspectos: (i) as diferenças na escala; (ii) os estágios no ciclo do projeto; (iii) a confiabilidade dos dados; e (iv) as diferentes abordagens e conceitos norteadores (Roche, 2002). Com relação às diferenças de escala, é interessante analisá-las comparativamente à intensidade da relação da empresa com o público beneficiado pelo programa (Figura 3). Mesmo que, à primeira vista, esta relação possa configurar-se como um tradeoff, ainda assim esta análise serve para apontar como as empresas se distribuem nos diferentes quadrantes. Cabe destacar que importa menos a avaliação individualizada de uma empresa do que a avaliação no conjunto. Contudo, algumas características de determinado programa receberão destaque, como forma de apontar melhorias ou tendências no campo da gestão social.

Neste caso, vemos que as empresas se distribuem praticamente respeitando a relação de alta intensidade de relacionamento para número reduzido de beneficiados diretos. Podemos destacar o Programa da Empresa D, que atende a grande número de pessoas - em torno de 470 crianças por ano - e consegue estabelecer um relacionamento medianamente intenso - mantém as crianças meio turno no programa, realiza acompanhamento com as crianças, interage com as escolas da comunidade, onde as crianças estudam e elabora atividades para os pais. Só não foi considerado 
mais intenso pelo fato de que o programa é realizado em meio turno, diferentemente do Programa A e do Programa G, nos quais os jovens - 52, no caso da empresa A e 40, no caso da empresa G ficam o dia todo no programa.

\begin{tabular}{|c|c|c|c|c|}
\hline $\begin{array}{l}\text { Intensidade da relação } \\
\text { com os beneficiados }\end{array}$ & & & & \\
\hline \multirow{2}{*}{ alta } & Programa A & & & \\
\hline & Programa G & & & \\
\hline módio & & Programa B & \multirow{2}{*}{ Programa D } & \\
\hline media & & Programa E & & \\
\hline \multirow{3}{*}{ baixa } & & & Empresa C * & \\
\hline & & & Empresa $\mathrm{F}^{*}$ & \\
\hline & $\begin{array}{c}\text { Poucos } \\
\text { beneficiados }\end{array}$ & & $\begin{array}{c}\text { Muitos } \\
\text { beneficiados }\end{array}$ & $\begin{array}{c}\text { Número de beneficiados } \\
\text { anualmente } * *\end{array}$ \\
\hline
\end{tabular}

Figura 1. Relação Entre Número de Beneficiados pelos Programas e Intensidade do Relacionamento da Empresa com os Beneficiados

* estas empresas não possuem um programa de destaque. Por esta razão, e pelo caráter de suas ações fica difícil mensurar o número efetivo de beneficiados; ** no primeiro quadrante foram considerados até 200 beneficiados diretos, no segundo, 400 e no terceiro, acima de 400 pessoas diretamente beneficiadas com o programa em questão.

O segundo fator de análise, o estágio no ciclo do projeto parece não ter influência no presente estudo, já que todos os programas foram editados mais de uma vez. O que pode influenciar é o tempo durante o qual a empresa vem desenvolvendo o programa, comparativamente ao grau de estruturação que este programa já conseguiu atingir.

O resultado esperado é o seguinte: quanto maior a idade do programa, mais estruturado ele fica. Neste caso, vemos que as empresas A, F e G estão dentro desta situação esperada. Outras duas situações aparecem: o caso das Empresas D e E; que se destacam positivamente, pois têm programas novos e relativamente bem estruturados - e as Empresas B e C, que pela idade dos seus programas, e comparativamente aos demais casos analisados, poderiam trabalhar na melhoria da estruturação dos seus programas.

O critério principal para definir o grau de estruturação baseou-se na quantidade e qualidade de informações sobre o programa de que cada empresa dispunha. Assim, foi possível verificar em que medida a empresa tem um programa social organizado e estruturado.

\begin{tabular}{|c|c|c|c|c|}
\hline \multicolumn{5}{|l|}{$\begin{array}{c}\text { Grau de estruturação dos } \\
\text { programas }\end{array}$} \\
\hline alto & & & Empresa A & \\
\hline médio & $\begin{array}{l}\text { Empresa D } \\
\text { Empresa E }\end{array}$ & $\begin{array}{l}\text { Empresa F } \\
\text { Empresa G }\end{array}$ & Empresa B & \\
\hline baixo & & & Empresa C & \\
\hline & Jovem & & Maduro & Idade do programa \\
\hline
\end{tabular}

Figura 2. Relação entre a Idade do Programa e o Grau de Estruturação do Programa

Os programas considerados jovens têm até 4 anos de operação (Empresa D - 3 anos; Empresa E - 4 anos), enquanto programas maduros têm acima de 8 anos (Empresa A - 11 anos; Empresa B - 9 anos; Empresa C - 10 anos). Na condição intermediária, os programas têm entre 4 e 8 anos de operação (Empresa F - 8 anos; Empresa G - 5anos).

A confiabilidade dos dados diz respeito à existência de formas sistematizadas de monitoramento e avaliação dos programas, além de documentação e formas de comunicação dos resultados. Para os casos em estudo, esta relação mostra-se bastante dispersa. Somente as empresas A e C mostram-se 
dentro do comportamento esperado; quanto maior a atuação em rede, maior a confiabilidade das informações sobre o programa.

As empresas D, E, F e G, por diferentes razões, tiveram graus de confiabilidade maiores do que o esperado para o seu grau de atuação em rede. A Empresa D tem grau de confiabilidade alto, pois a captação de recursos provenientes do Fundo de Amparo à Cultura faz com que a empresa dedique muita atenção para o monitoramento dos resultados alcançados, como forma de prestação de contas ao governo. Os casos das empresas $F$ e $G$ são semelhantes. A Empresa F tem maior confiabilidade das informações, pois possui certificação da norma SA 8.000. Já a empresa $G$ tem de se adequar às exigências da franqueadora do seu programa. A única exceção é a empresa $E$ que, apesar de não ter a exigência legal das empresas acima citadas, também acompanha e avalia, minuciosamente, o andamento do programa. Além disso, esta empresa tem sido alvo de estudo de muitos pesquisadores; com isto, tem aproveitado os resultados destas avaliações.

Confiabilidade das informações sobre o programa

\begin{tabular}{cccc} 
alto & Empresa F & $\begin{array}{c}\text { Empresa D } \\
\text { Empresa E }\end{array}$ & Empresa A \\
\cline { 2 - 3 } baixo & Empresa G & \\
\cline { 2 - 3 } & Empresa C & Empresa B & \\
baixa & média & alta & $\begin{array}{c}\text { Grau de atuação das } \\
\text { parcerias em rede }\end{array}$
\end{tabular}

Figura 3. Relação entre o Grau de Atuação das Parcerias em Rede e a Confiabilidade das Informações Sobre o Programa

Esta avaliação foi construída qualitativamente a partir das evidências coletadas em cada caso.

As diferentes abordagens e conceitos norteadores mostram preocupações diferentes quanto aos aspectos de planejamento, implementação, monitoramento e avaliação dos programas. Como podemos observar, tanto pela revisão teórica, quanto pelos resultados empíricos deste estudo, a questão da efetiva participação dos beneficiados tem-se mostrado como fator determinante da geração do capital social, a partir dos programas das empresas privadas.

Além da participação do público externo, beneficiado com o programa, faz-se necessário analisar a participação e o envolvimento de outro público: o interno. Esta análise mostra que as empresas têm apresentado comportamento homogêneo quanto à variável participação. Tanto para o público externo, quanto para o interno, foi analisado o grau de participação dos envolvidos nas diferentes etapas do programa. Assim, as empresas, de forma geral, precisam trabalhar mais em formas de envolvimento dos funcionários e do público externo. Nas empresas B e F, todos os funcionários se envolvem nas ações sociais. Já na empresa $C$, a participação nas ações da empresa mais ativa é do grupo de funcionários que compõem o comitê que trata das demandas que chegam à empresa. No entanto, pela natureza assistencial e efêmera de algumas ações, o envolvimento do público externo é baixo.

No outro extremo, as demais empresas possuem baixo grau de envolvimento dos funcionários e também podem melhorar a preocupação com o envolvimento das comunidades nas diferentes fases do programa. 


\begin{tabular}{|c|c|c|c|c|}
\hline \multicolumn{5}{|l|}{$\begin{array}{c}\text { Grau de participação dos } \\
\text { beneficiados nas etapas do } \\
\text { programa }\end{array}$} \\
\hline \multicolumn{5}{|l|}{ alto } \\
\hline \multirow{2}{*}{ médio } & Empresa A & Empresa E & \multirow{2}{*}{ Empresa B } & \\
\hline & Empresa D & Empresa G & & \\
\hline \multirow[t]{2}{*}{ baixo } & & Empresa C & Empresa F & \\
\hline & baixo & médio & alto & $\begin{array}{c}\text { Grau de participação dos } \\
\text { funcionários das empresas nos } \\
\text { programas }\end{array}$ \\
\hline
\end{tabular}

Figura 4. Relação o Grau de Participação dos Funcionários das Empresas nos Programas Sociais e o Grau de Participação dos Beneficiados nas Diferentes Etapas dos Programas

Esta avaliação foi construída qualitativamente a partir das evidências coletadas em cada caso. Fonte: presente estudo.

Em suma, podemos dizer que os programas analisados carecem da necessidade de aumentar o envolvimento dos públicos interno (funcionários) e externo (comunidade).

Outro aspecto evidenciado diz respeito à forma isolada como as empresas vêm atuando. As estruturas de rede são fracas, estabelecendo trocas e parcerias instrumentais, na maioria dos casos com fornecedores da empresa. As iniciativas de parcerias com outros atores, como poder público, universidade e ONGs são pouco expressivas. Além disso, as empresas ainda enxergam a questão de parceria associada, quase exclusivamente, com a possibilidade de obtenção de recursos financeiros.

Finalizada esta análise comparativa entre os diferentes aspectos dos casos em estudo, faremos agora breve resumo da análise quanto às dimensões do capital social (Tabela 4). 
Tabela 4

\section{Quadro Resumo das Características Predominantemente Relacionadas ao Capital Social, Reveladas na Análise dos Casos}

\begin{tabular}{|c|c|c|c|c|c|c|c|c|c|}
\hline & Categorias de análise & Empresa A & Empresa B & Empresa C & Empresa D & Empresa E & Empresa F & Empresa G & Conclusão \\
\hline 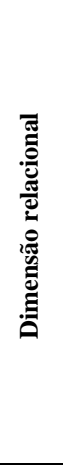 & 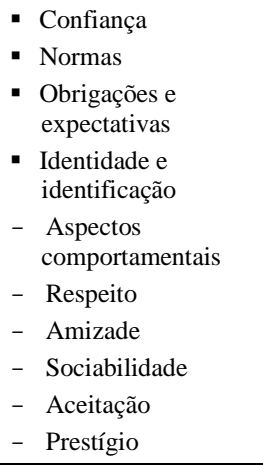 & $\begin{array}{l}\diamond \text { As normas e a } \\
\text { identidade com a } \\
\text { empresa são } \\
\text { elementos de } \\
\text { destaque do } \\
\text { programa; } \\
\diamond \text { Necessidade de } \\
\text { fortalecimento dos } \\
\text { laços dos alunos com } \\
\text { suas comunidades. }\end{array}$ & $\begin{array}{l}\diamond \text { Envolvimento direto } \\
\text { de todos os níveis } \\
\text { hierárquicos; } \\
\diamond \text { Necessidade de } \\
\text { maior envolvimento } \\
\text { da comunidade, } \\
\text { buscando o } \\
\text { empoderamento da } \\
\text { mesma. }\end{array}$ & $\begin{array}{l}\diamond \text { Dificuldades com } \\
\text { relação à } \\
\text { participacãão } \\
\text { voluntária de seus } \\
\text { funcionários; } \\
\diamond \text { Possibilidade de } \\
\text { melhorias na } \\
\text { sistematização das } \\
\text { ações e } \\
\text { monitoramento das } \\
\text { mesmas }\end{array}$ & $\begin{array}{l}\diamond \text { Baixo grau de } \\
\text { participação, tanto } \\
\text { da direção, quanto } \\
\text { dos funcionários da } \\
\text { empresa; } \\
\diamond \text { Bom monitoramento } \\
\text { dos resultados do } \\
\text { programa. }\end{array}$ & $\begin{array}{l}\diamond \text { Necessidade de } \\
\text { maior envolvimento } \\
\text { do público interno; } \\
\diamond \text { Possibilidade de } \\
\text { ampliar o projeto } \\
\text { através da franquia. }\end{array}$ & $\begin{array}{l}\diamond \text { Envolvimento direto } \\
\text { de todos os níveis } \\
\text { hierárquicos; } \\
\diamond \text { As impressões sobre } \\
\text { os resultados das } \\
\text { ações são discutidas } \\
\text { com o líder do } \\
\text { bairro, unicamente. }\end{array}$ & $\begin{array}{l}\diamond \text { Interação existente - } \\
\text { porém ainda fraca - } \\
\text { com a comunidade; } \\
\diamond \text { Aumento da carga } \\
\text { horária do curso } \\
\text { visando trabalhar } \\
\text { melhor o aspecto } \\
\text { comportamental. }\end{array}$ & $\begin{array}{l}\diamond \text { Boa atuação sobre } \\
\text { aspectos } \\
\text { comportamentais; } \\
\diamond \text { Necessidade de } \\
\text { maior envolvimento } \\
\text { dos públicos interno } \\
\text { e externo }\end{array}$ \\
\hline 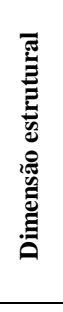 & $\begin{array}{l}\text { - Conexões da rede } \\
\text { - Configuração da rede } \\
\text { - Adequação da } \\
\text { organização } \\
\text { - Presença ou não de } \\
\text { - laços entre os atores } \\
\text { - Densidade } \\
\text { - } \quad \text { Conectividade }\end{array}$ & $\begin{array}{l}\diamond \text { Parceria com órgão } \\
\text { público e a rede } \\
\text { RECRIA; } \\
\diamond \text { Promove a "mistura" } \\
\text { de dois públicos } \\
\text { diferentes quanto à } \\
\text { renda }\end{array}$ & $\begin{array}{l}\diamond \text { Parcerias com a } \\
\text { universidade local e } \\
\text { com fornecedores; } \\
\diamond \text { Intenção de } \\
\text { desenvolver } \\
\text { parcerias que } \\
\text { envolvam recursos } \\
\text { financeiros. }\end{array}$ & $\begin{array}{l}\diamond \text { Parcerias efêmeras; } \\
\diamond \text { Existe a percepção } \\
\text { da importância de } \\
\text { trocar idéias e de } \\
\text { constituir espaços de } \\
\text { discussão }\end{array}$ & $\begin{array}{l}\diamond \text { Dependência } \\
\text { financeira de } \\
\text { recursos do governo; } \\
\diamond \text { Poucos laços entre } \\
\text { os parceiros do } \\
\text { projeto. }\end{array}$ & $\begin{array}{l}\diamond \text { Boa conectividade } \\
\text { no meio empresarial, } \\
\text { para a divulgação do } \\
\text { projeto; } \\
\diamond \text { Intenção de } \\
\text { desenvolver } \\
\text { parcerias que } \\
\text { envolvam recursos } \\
\text { financeiros. }\end{array}$ & $\begin{array}{l}\diamond \text { Fraca estrutura de } \\
\text { rede: existem } \\
\text { parcerias somente } \\
\text { com fornecedores }\end{array}$ & $\begin{array}{l}\diamond \text { Parcerias } \\
\text { instrumentais; } \\
\diamond \text { Acompanhamento } \\
\text { dos egressos; } \\
\diamond \text { Intenção de } \\
\text { desenvolver } \\
\text { parcerias que } \\
\text { envolvam recursos } \\
\text { financeiros. }\end{array}$ & $\begin{array}{l}\diamond \text { Necessidade de } \\
\text { fortalecer as } \\
\text { parcerias além da } \\
\text { questão financeira e } \\
\text { de atuar em rede } \\
\diamond \text { Necessidade de } \\
\text { construção de } \\
\text { espaços de trocas } \\
\text { idéias e de discussão }\end{array}$ \\
\hline 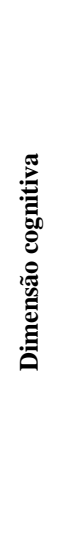 & $\begin{array}{l}\text { - Códigos e linguagens } \\
\text { compartilhadas } \\
\text { - } \text { Narrativas } \\
\text { compartilhadas } \\
\text { - Visões } \\
\text { compartilhadas } \\
\text { - Interpretações } \\
\text { - Sistemas de } \\
\text { significado } \\
\text { - Habilidade de acessar } \\
\text { outras pessoas e } \\
\text { informaçôes } \\
\text { - Linguagem } \\
\text { compartilhada } \\
\text { - Mitos, histórias, } \\
\text { lendas e metáforas }\end{array}$ & $\begin{array}{l}\diamond \text { As interpretações } \\
\text { com relação aos } \\
\text { objetivos da escola } \\
\text { variam } \\
\text { significativamente; } \\
\diamond \text { Pode ampliar o } \\
\text { envolvimento dos } \\
\text { funcionários, criando } \\
\text { momentos de trocas } \\
\text { e atividades de } \\
\text { integração. }\end{array}$ & $\begin{array}{l}\diamond \text { Falta uma visão } \\
\text { unificada do que se } \\
\text { constitui uma } \\
\text { "criança carente"; } \\
\diamond \text { Necessidade de } \\
\text { planejar } \\
\text { estrategicamente o } \\
\text { futuro do projeto. }\end{array}$ & $\begin{array}{l}\diamond \text { Necessidade de } \\
\text { construir uma visão } \\
\text { compartilhada sobre } \\
\text { como deve ser a } \\
\text { atuação da empresa } \\
\text { socialmente. }\end{array}$ & $\begin{array}{l}\diamond \text { Pouco } \\
\text { aproveitamento dos } \\
\text { resultados do } \\
\text { programa para o } \\
\text { aprendizado do } \\
\text { público interno da } \\
\text { empresa; } \\
\diamond \text { Atuação voltada para } \\
\text { o marketing social. }\end{array}$ & $\begin{array}{l}\diamond \text { Conseguiu contornar } \\
\text { a baixa receptividade } \\
\text { inicial dos próprios } \\
\text { funcionários; } \\
\diamond \text { Pode ampliar o } \\
\text { envolvimento dos } \\
\text { funcionários, criando } \\
\text { momentos de trocas } \\
\text { e atividades de } \\
\text { integração. }\end{array}$ & $\begin{array}{l}\diamond \text { O significado das } \\
\text { ações está vinculado } \\
\text { à sobrevivência da } \\
\text { empresa, uma vez } \\
\text { que a } \\
\text { responsabilidade } \\
\text { social é um dos } \\
\text { eixos do sistema de } \\
\text { qualidade }\end{array}$ & $\begin{array}{l}\diamond \text { Resgate da } \\
\text { identidade da } \\
\text { empresa e da } \\
\text { condição de } \\
\text { cidadãos dos jovens; } \\
\diamond \text { Não prioriza o } \\
\text { marketing social. }\end{array}$ & $\begin{array}{l}\diamond \text { Necessidade de } \\
\text { construção de uma } \\
\text { visão compartilhada } \\
\text { - no âmbito de rede - } \\
\text { sobre a atuação das } \\
\text { empresas no campo } \\
\text { da gestão social. }\end{array}$ \\
\hline
\end{tabular}


O desenvolvimento local exige, pois, nova forma de gestão no campo social, onde não apenas o poder governamental local, mas diferentes atores desempenham o papel de promotores e articuladores de políticas públicas, desde a formulação até a implementação, do monitoramento à avaliação das ações.

Faremos algumas considerações no sentido de promover mudanças na forma de atuação das empresas privadas no campo da gestão social. São elas explicitadas a seguir.

a) Uma das preocupações dos programas deveria ser o incentivo à participação nas diversas instâncias, principalmente no âmbito local: vizinhos, comunidade, município e região. A estratégia de desenvolvimento acontece a partir da agenda local e das capacidades dos indivíduos, associações e instituições locais de criarem seus caminhos. Não pretende negar a importância do contexto, mas enfatizo a importância do conhecimento, investimento, criatividade e controle local (Neumann \& Neumann, 2004).

b) Os programas deveriam trabalhar com enfoque mais acentuado nas virtudes sociais e nas virtudes individuais. Entre os hábitos culturais que constituem virtudes, nem todos contribuem para o capital social, já que alguns podem ser exercidos por indivíduos, isoladamente. Somente elementos como, por exemplo, confiança, honestidade, cooperativismo e senso de dever para com os outros, por emergirem de contexto social, é que contribuem para a formação de capital social. Estas virtudes sociais são, portanto, críticas para o desenvolvimento das virtudes individuais.

c) Atuar no fortalecimento da família, através de programas destinados não só a crianças e jovens, mas também, aos adultos. A forma mais fundamental de capital social é a família; ela é o primeiro tijolo na geração deste capital na sociedade (Putnam, 2002).

d) Ajudar no emponderamento das comunidades, fortalecendo o elo entre a família e o Estado. O fortalecimento da comunidade é fundamental para que esta sirva de elo entre a família e o Estado.

e) Ampliar as parcerias com o poder público, no sentido de expandir o conhecimento das diferentes realidades do município e região e, assim, poder melhor direcionar os recursos e esforços. Tendo em vista a esfera local de governo, vemos que os municípios têm possibilidades - dentro dos limites de sua autonomia relativa e de suas competências - de instituir canais e mecanismos de fomento da comunidade cívica (Santos, 2001).

A partir do que foi exposto, vemos que o tema do desenvolvimento local indica a necessidade de combinar processos e agendas segmentadas, produzindo alianças estruturadas por redes de atores sociais, institucionais e governamentais que se organizem de forma participativa, integrem ações e desencadeiem projetos econômicos sustentáveis.

A responsabilidade social corporativa é um fenômeno social, cultural e econômico, que vem crescendo em todas as regiões do país. Por isso, vale ressaltar que o objetivo da pesquisa foi, prioritariamente, a análise desse fenômeno como forma de compreender em que medida a atuação de empresas privadas, no campo da gestão social, está contribuindo para o fortalecimento do capital social das comunidades atingidas, muito mais do que a ambição de tornar essa análise uma teoria passível de ser replicada em outros contextos e realidades, ainda que isso possa ser possível e até desejável.

\section{CONSIDERAÇÕES FINAIS}

Evidencia-se, hoje, a necessidade de espaços interdisciplinares de discussão no campo social, para diversificar a atuação dos diferentes atores, distribuindo melhor os esforços, de forma a atingir públicos que atualmente não estão sendo contemplados pelos programas, principalmente aqueles implementados por empresas privadas. Além disso, estes espaços podem aumentar o capital social em 
todas as suas dimensões, uma vez que promovem a troca de experiências, fortalecem os relacionamentos e melhoram a estrutura dos programas através da atuação em redes e não mais de forma isolada. Existe atualmente, na região da Serra Gaúcha, uma sobreposição de programas, atuando quase exclusivamente para o público infantil. Contudo, esta não é peculiaridade da região. Pesquisas, tais como a do IPEA (2003) e da Fundação Semear (2003), já mostraram que isso tem sido uma realidade nacional. As empresas deveriam fazer um levantamento das ações que já existem na comunidade escolhida para que não haja sobreposição de objetivos ou públicos atingidos. Além disso, cumpre estabelecer critérios para a escolha da comunidade e do problema social a ser tratado.

Por isso, faz-se necessário criar uma rede de atuação no campo social, onde a sociedade seja vista como um todo e não de forma fragmentada. Mesmo que a atuação de determinado programa seja focada num único público, como, por exemplo, o infantil, a idéia seria que, dentro da rede, outro ator desenvolvesse um programa com outro público relacionado diretamente a estas crianças beneficiadas, como, por exemplo, programas voltados para os pais ou responsáveis destas crianças, ou para as escolas onde estas crianças estudam ou para a comunidade onde esta criança mora etc.

Além da importância de agir de forma mais ampla, atingindo o ser humano inserido no seu núcleo familiar, é preciso superar a cultura clientelista, na qual as pessoas deixam de ser clientes de serviços sociais para serem cidadãos construtores do seu futuro. As comunidades devem assumir o papel principal na mudança de comportamentos, relações sociais e ambientes físico e econômico; elas são os principais agentes da sua qualidade de vida. Ầ empresa cabe utilizar uma abordagem que permita a participação ativa da comunidade.

Outro aspecto importante diz respeito ao formato dos grupos de trabalho voluntário nos programas de empresas privadas. Nos casos em que os programas estão essencialmente calcados no trabalho de voluntários-funcionários, as empresas têm encontrado dificuldades de envolvimento e "renovação" deste quadro, por serem sempre as mesmas pessoas que participam. Por outro lado, não é possível exigir de trabalhadores voluntários o mesmo grau de dedicação e comprometimento de profissionais remunerados para a realização do trabalho social; o trabalho voluntário gera sobrecarga de trabalho, de modo que não raro essas pessoas passam em média 12 horas envolvidas com a empresa.

Não raro as exigências da empresa assumem caráter contraditório, na medida em que, de um lado, ela exige que os funcionários estejam em formação permanente e, de outro, até mesmo por questões de imagem, ela deseja que os mesmos participem de atividades voluntárias, o que acaba dificultando a participação destes em suas próprias comunidades.

Não se trata aqui de abolir os grupos de voluntários das empresas. No entanto, estas poderiam estudar alternativas para eles. Ao atuar no campo social, a empresa colhe muitos frutos, mesmo aqueles - em alguns casos - não declarados, como a melhoria da imagem, o fortalecimento da marca e a melhoria da reputação perante fornecedores, funcionários e clientes. Não seria o caso de permitir uma contrapartida à atuação destes funcionários como voluntários nos programas da empresa? As atividades poderiam ser desenvolvidas - sempre que possível - em horário de trabalho, ou poderia haver uma flexibilização do horário de trabalho via banco de horas, ou algum outro tipo de compensação.

Paralelamente a isso, a empresa poderia fomentar outras formas de participação destes funcionários na comunidade, organizando mutirões, eventos comunitários, reuniões, como forma de retribuir a participação deles nas atividades voluntárias que elevam o nome da empresa.

Estaremos verdadeiramente fazendo "gestão social", quando a sociedade entrar em processo de negociação dos rumos do desenvolvimento com o Estado e o Mercado e quando conseguirmos construir mecanismos de controle social sobre estes dois atores. A gestão social pressupõe que os atores são sujeitos protagonistas do desenvolvimento.

Artigo recebido em 09.04.2009. Aprovado em 15.12.2009. 


\section{REFERÊNCIAS BIBLIOGRÁFICAS}

Andrade, J. A., \& Mendonça, J. R. C. (2002, outubro). Responsabilidade social e construção da imagem corporativa: entre instrumentalidade e substantividade. Anais da Assembleia do Conselho Latino-Americano de Escolas de Administração, Porto Alegre, RS, Brasil, 37.

Ashley, P. A. (Coord.). (2002). Ética e responsabilidade social nos negócios. São Paulo: Saraiva.

Baiardi, A., \& Laniado, R. N. (2002). A ação social extrafirma do empresariado baiano. In T. Fischer (Org.), Gestão do desenvolvimento e poderes locais: marcos teóricos e avaliação (pp. 314-330). Salvador: Casa da Qualidade.

Bandeira, P. S. (2003). Algumas hipóteses sobre as causas das diferenças regionais quanto ao capital social no Rio Grande do Sul. In S. M. Correa (Org.), Capital social e desenvolvimento regional (pp. 15-59). Santa Cruz do Sul: EDUNISC.

Bardin, L. (1977). Análise de conteúdo. Lisboa: Edições 70.

Bourdieu, P. (2003a). O poder simbólico (6a ed.). Rio de Janeiro: Bertrand.

Bourdieu, P. (2003b). Razões práticas: sobre a teoria da ação (4a ed.). Campinas: Papirus.

Carrion, R. M. (2003). Discurso e práticas em responsabilidade social: análise das práticas de gestão das relações de trabalho em empresas filiadas ao Instituto Ethos e signatárias do Global Compact, no Rio Grande do Sul. Projeto de Pesquisa não publicado, Programa de PósGraduação em Administração, Núcleo Interdisciplinar de Pesquisas e Estudos Sobre o Terceiro Setor, Universidade Federal do Rio Grande do Sul. Porto Alegre, Brasil.

Coleman, J. S. (1990). Foundations of social theory. Cambridge: Harvard University Press.

Constantini, G. (2002). Experiências de avaliação em debate. In T. Fischer (Org.), Gestão do desenvolvimento e poderes locais: marcos teóricos e avaliação (pp. 220-228). Salvador: Casa da Qualidade.

França, G. C., Filho (2003, dezembro). Gestão social: um conceito em construção. Anais do Colóquio Internacional Sobre Poder Local, Salvador, BA, Brasil, 9.

Fukuyama, F. (1996). Confiança: as virtudes sociais e a criação da prosperidade. Rio de Janeiro: Rocco.

Fukuyama, F. (2000). A grande ruptura: a natureza humana e a reconstituição da ordem social. Rio de Janeiro: Rocco.

Fundação Semear. (2003). Relatório de pesquisa sobre responsabilidade social. Novo Hamburgo: Autor.

Granovetter, M. (1992): Problems of explanation in economic sociology. In N. Nohria \& R. Eccles (Eds.), Networks and organizations: structure, form and action. Boson, MA: Harvard Business School Press.

Guia da Sustentabilidade e Cidadania Corporativa. (2005, agosto/setembro). Revista Amanhã, 213(Supl.), ano 19.

Hirschman, A. O. (1984). A dissenters confession: the strategy of economic development revisited. In G. M. Meier \& D. Seers (Eds.), Pioneers in development. Washington, DC: Oxford University Press. 
Instituto de Pesquisa Econômica Aplicada. (2002). Ação social das empresas: avanços e desafios. Recuperado em 08 maio, 2003, de http://www.ipea.gov.br/asocial

Macke, J. (2006). Programas de responsabilidade social corporativa e capital social: contribuição para o desenvolvimento local? Tese de doutorado, Universidade Federal do Rio Grande do Sul, Porto Alegre, RS, Brasil.

Macke, J., Vallejos, R. V., \& Sarate, J. A. R. (2010). Collective competence and social capital analysis in collaborative networks. Journal of Systemics, Cybernetics and Informatics, 8(3), 18-23.

Melo, F. P., Neto, \& Froes, C. (1999). Responsabilidade social e cidadania empresarial: a administração do terceiro setor. Rio de Janeiro: Qualimark.

Melo, F. P., Neto, \& Froes, C. (2002) Gestão da responsabilidade social corporativa: o caso brasileiro. Rio de Janeiro: Qualimark.

Milani, C. (2004). Teorias do capital social e desenvolvimento local: lições a partir da experiência de Pintadas (Bahia, Brasil). Recuperado em 08 junho, 2004, de http://www.adm.ufba.br/capitalsocial

Monastério, L. M. (2003). Medindo o capital social: uma análise das regiões do Rio Grande do Sul. In S. M. S. Correa (Org.), Capital social e desenvolvimento regional (pp. 61-84). Santa Cruz do Sul: EDUNISC.

Nahapiet, J., \& Ghoshal, S. (1998). Social capital, intellectual capital and the organizational advantage. Academy of Management Review, 23(2), 242-266.

Neumann, L. T. V., \& Neumann, R. A. (2004). Repensando o investimento social: a importância do protagonismo comunitário [Coleção Investimento Social]. São Paulo: Global; Instituto para Desenvolvimento de Investimento Social.

Onyx, J., \& Bullen, P. (2000). Measuring social capital in five communities. The Journal of Applied Behavioral Science, 36(1), 23-42.

Portes, A. (1998). Social capital: its origins and application in modern sociology. Annual Review of Sociology, 24(1), 1-24.

Putnam, R. D. (2002). Comunidade e democracia: a experiência da Itália moderna (3a ed.). Rio de Janeiro: FGV.

Roche, C. (2002). Avaliação de impacto dos trabalhos de ONGs: aprendendo a valorizar as mudanças (2a ed.). São Paulo: Cortez, ABONG.

Santos, O. A., Jr. (2001). Democracia e governo local: dilemas e reforma municipal no Brasil. Rio de Janeiro: Revan/FASE.

Scherer-Warren, I. (2002). Redes e sociedade civil global. In S. Haddad (Org.), ONGs e universidades: desafios para a cooperação na América Latina (pp. 63-92). São Paulo: Petrópolis.

Schommer, P. C. (2000). Investimento social das empresas: cooperação organizacional num espaço compartilhado. Dissertação de mestrado, Universidade Federal da Bahia, Salvador, BA, Brasil.

Schommer, P. C. (2002). Investimento social nas empresas: cooperação organizacional num espaço compartilhado. In T. Fischer (Org.), Gestão do desenvolvimento e poderes locais: marcos teóricos e avaliação (pp. 91-109). Salvador: Casa da Qualidade. 
Serva, M. (1999). A racionalidade substantiva demonstrada na prática administrativa. Revista de Administração de Empresas, 37(5), 7-23.

Silveira, C. M. (2002). Desenvolvimento local: concepções, estratégias e elementos para avaliação de processos. In T. Fischer (Org.), Gestão do desenvolvimento e poderes locais: marcos teóricos e avaliação (pp. 239-244). Salvador: Casa da Qualidade.

Silveira, C., Bocayuva, C., \& Zapata, T. (2001). Ações integradas e desenvolvimento local: tendências, oportunidades e caminhos. São Paulo: Polis/Programa, Gestão Pública e Cidadania/EAESP/FGV.

Skidmore, D. (2001). Sociedade civil, capital social e desenvolvimento econômico. In A. A. Abreu (Org.), Transição em fragmentos: desafios da democracia no final do século XX (pp. 129-152). Rio de Janeiro: FGV.

Tocqueville, A. (2004). A democracia na América. São Paulo: Martins Fontes.

Vallejos, R. V., Macke, J., Olea, P. M., \& Toss, E. (2008). Collaborative networks and social capital: a theoretical and practical convergence. International Federation for Information Processing, a Springer Series in Computer Science, 283, 43-52.

World Bank. (2004). Social capital for development. Recuperado em 27 abril, 2004, de http://www1.worldbank.org/prem/poverty/scapital/index.htm

Yin, R. K. (1994). Case study research: design e methods (2a ed.). London: Sage Publications. 